\title{
A Comparative Analysis of Back Handspring and Forward Handspring with Angular Kinematics Variables
}

\author{
Rajpoot Y. S ${ }^{\text {* }}$, Rathor Sandesh Kumar ${ }^{2}$ \\ ${ }^{1}$ Associate Professor, LNIPE, Gwalior (M.P), India \\ ${ }^{2}$ Research Scholar, LNIPE, Gwalior (M.P), India
}

DOI: $10.36348 /$ jaspe.2022.v05i01.002

| Received: 09.12.2021 | Accepted: 25.01.2022 | Published: 30.01 .2022

*Corresponding author: Rajpoot Y. S

Associate Professor, LNIPE, Gwalior (M.P), India

\section{Abstract}

The purpose of this study was to investigate the difference of kinematic variables between two. Back handspring and Forward Handspring performance of 05 male gymnasts of L.N.I.P.E, Gwalior was recorded. They aged between 19 to 25 years. Purposive sampling technique was used for choosing highly skilled gymnast. These gymnasts had 7 to 12 years training experience and were technically sound on the stated skills. Videography technique was employed in order to register the performance of the subjects in Back Handspring and Forward Handspring. The Canon - 70D camera was used with the frequency of 24 frames per second and the subjects were video graphed in horizontal plane (sagittal plane) from the left side. Each subject was given three trails and the best trail was used for analysis. The selected phases were taken out from the video by using snipping tool software. From the photographic sequence, the stick figures of the selected movements and there angles were located by kinovea software. The data was analyzed by using Independent $\mathrm{T}$ Test. There were two skills that were Back handspring and Forward handspring which was further divided into two phases, Initial Phase and Ground Touch Phase and Shoulder joint, Elbow Joint and wrist joint were selected as the angular kinematics variables. The level of significance was set at 0.05 . The results revealed that all selected angular kinematic variables at all the phase had shown insignificant deference with the Back Handspring and Forward Handspring. On the basis of results it is concluded that that the performance of any games and sports depending upon the multidimensional factors such as physical factors, physiological factors, psychological factors and so many other factors.

Keywords: Biomechanics, Angular kinematics, Back Handspring, and Forward Handspring.

Copyright ( 2022 The Author(s): This is an open-access article distributed under the terms of the Creative Commons Attribution 4.0 International License (CC BY-NC 4.0) which permits unrestricted use, distribution, and reproduction in any medium for non-commercial use provided the original author and source are credited.

\section{INTRODUCTION}

Correct execution of body movement leads to a successful sports performance. Biomechanics is "the study of the structure and function of biological systems by means of the methods of mechanics" (Hatze, 1974). It is most helpful in improving the performance in terms of correct body position in sports or activities where technique is the dominant factor rather than physical structure or physiological capacity (Joshi, H. C., 2014). Since biomechanics is essentially the science of movement technique. In the recent years, greater stress has been laid on quality rather than quantity of training (Singh D et al., 2011). The coaches and teachers of physical education want their athletes to extract maximum achievement from their training procedure without causing too much strain on them (Khalil, 1986). It may be necessary to develop programs of study for the training of technique in sports biomechanics, technicians who can provide the kind of services sought by sporting bodies (Hay, 1984). Gymnastics are currently training close to their bio-physical limits and with evolving code of point (F.I.G, 2013) and desire to continually strive for complex and innovation moments. In gymnastics, every skill is having biomechanical orientation. In this context, the mechanical principles such as motion, speed, center of gravity, angle of takeoff, push-off, landing angle play an important role related with the performance. The ultimate aim of the coaching biomechanics interface in gymnastics training is to make training more effective, efficient and safe.

Back handspring is an element which is performed on floor exercise. It is a basic movement for learning the advance skill involving after the back handspring (e.g.- back handspring to back sato, straight 
boby, $360^{\circ}$, etc.). back handspring is an "a" class element come under the EGR- II i.e. under swing as per the "MAG coad of point 2016". Back roll, Handstand, back turnover are the prerequisites for learning this element.

Forward handspring is an element which is performed on floor exercise. It is a basic movement for learning the advance skill involving after the forward handspring (e.g.- hand front, double hand front, hand front to $360^{\circ}$, etc.). Forward handspring is an "a" class element come under the EGR- II i.e. under swing as per the "MAG code of point 2016". Forward rolls, Handstand, Front turn over are the prerequisites for learning this element.

The purpose of the present study was to determine the impact force and kinematic analysis of forward hand spring and back hand spring technique on floor exercise in artistic gymnastics. This was selected keeping some important points in the mind by the scholar. Artistic gymnastics is a technical sport and technique plays an important role to learn the skill. In gymnastics each and every skill is technique oriented. Forward hand spring and back hand spring is a basic and important skill in artistic gymnastics, and large number of gymnast performs this skill on tumbling in series routine. Forward hand spring and back hand spring hand placement phase is also a very important phase because these phase is very important to learn others skill, as most of the other skills hand placement are very much similar to the hand placement phase of forward and back hand spring. As scholar I felt that a large number of gymnast perform these skill without knowing the technical aspects of forward and back hand spring and they don't have the logical answer, same is the condition of coaches. So the gymnast performs this skill by hook and crook. This technique is a basic skill in gymnastics, and when gymnasts have mastery on this skill then he can learn some other difficult skills very easily.

\section{METHODOLOGY}

The methodology of the study consist of selection of subjects, selection of variables, criterion measures, filming protocol, testing procedure and the technique employed for analysis of data.

\section{Selection of Subjects}

Back handspring and Forward handspring performance of 05 male gymnasts of L.N.I.P.E, Gwalior was recorded. They aged between 19 to 25 years. Purposive sampling technique was used for choosing highly skilled gymnast. These gymnasts had 7 to 12 years training experience and were technically sound on the stated skills. Since the gymnast had been trained for a considerable period of time, they were considered skilled and their technique was treated as stabilized. All the subjects were explained the purpose of the study and were requested to put in their best during each attempt or trial.

\section{Experimental Filming Protocol}

Videography technique was employed in order to register the performance of the subjects in Back Handspring and Forward Handspring. The Canon - 70D camera was used with the frequency of 24 frames per second and the subjects were video graphed in horizontal plane (sagittal plane) from the left side. Each subject was given three trails and the best trail was used for analysis.

\section{Procedure for collection of data}

Videography technique was employed in order to register the performance of the subjects in Back Handspring and Forward Handspring in the study. Selected kinematics variables and two selected phases (Figure 1) of whole skill i.e. positioning of Initial Phase and Ground Support Phase were analysed. The selected phases were taken out from the video by using snipping tool software. From the photographic sequence, the stick figures of selected movements were prepared by using joint point method and the selected angular kinematic variables were obtained at Initial Phase and Ground Support phase. The angles of selected joints were measured by the help of kinovea. The performance of each subject back handspring and forward handspring on floor was collected on the basis of three judge's evaluation. The average of three judges was considered as the final point obtained by each gymnast. Further, to easy calculation it was reduced out of ten points. The evaluating criteria are mentioned in Table 1.

\section{Statistical Technique}

For the purpose of the study, descriptive statistics and Independent T-test was employed by 'Statistical Package for Social Sciences' (SPSS) software version 20 . The level of significance will be set at .05 level.

Evaluating criteria of the back handspring and forward handspring performance of the gymnasts

1. Initial Phase

2. Ground Support phase

\section{RESULTS AND DISCUSSION OF FINDING}

The Independent T-Test was employed on selected angular Kinematics variables are presented separately.

The results of the Independent T-Test which were obtained in order to ascertain the difference between the Kinematic variables i.e. the angle at shoulder joint, angle at elbow joint, and angle at Wrist joint in two different phases (Initial Phase and Ground Touch Phase) in Back Handspring and Forward Handspring, the descriptive statistics of the concerned variables are mentioned below: 
Rajpoot Y. S \& Rathor Sandesh Kumar., J Adv Sport Phys Edu, Jan, 2022; 5(1): 7-10

Table 1: Kinematical Variables Descriptive Statistics of Back Handspring and Forward Handspring at Different Phase

\begin{tabular}{|l|l|l|l|l|}
\hline Groups & N & Mean & Std. Deviation \\
\hline Shoulder Joint (Initial Phase) & Back Handspring & 5 & 21.6000 & 1.81659 \\
\cline { 2 - 5 } & Forward Handspring & 5 & 48.6000 & 6.80441 \\
\hline \multirow{2}{*}{ Wrist Joint (Initial Phase) } & Back Handspring & 5 & 119.2000 & 9.41807 \\
\cline { 2 - 5 } & Forward Handspring & 5 & 118.2000 & 4.96991 \\
\hline \multirow{2}{*}{ Elbow Joint (Initial Phase) } & Back Handspring & 5 & 180.0000 & 0.00000 \\
\cline { 2 - 5 } & Forward Handspring & 5 & 178.8000 & 2.68328 \\
\hline Shoulder Joint (Ground Touch Phase) & Back Handspring & 5 & 177.0000 & 4.63681 \\
\cline { 2 - 5 } & Forward Handspring & 5 & 174.8000 & 6.83374 \\
\hline Wrist Joint (Ground Touch Phase) & Back Handspring & 5 & 52.8000 & 3.03315 \\
\cline { 2 - 5 } & Forward Handspring & 5 & 50.0000 & 3.80789 \\
\hline \multirow{2}{*}{ Elbow joint (Ground Touch Phase) } & Back Handspring & 5 & 172.6000 & 9.71082 \\
\cline { 2 - 5 } & Forward Handspring & 5 & 174.2000 & 7.91833 \\
\hline
\end{tabular}

Above table clearly show the mean and Standard Deviation mean of Back Handspring and
Forward Handspring at the two different phases i.e Initial Phase and Ground Touch Phase.

Table 2: Independent T Test of Back Handsring and Forward Handspring at Different Phase

\begin{tabular}{|l|l|l|l|l|l|l|}
\hline Variables & & \multicolumn{2}{l}{$\begin{array}{l}\text { Levene's Test for } \\
\text { Equality of } \\
\text { Variances }\end{array}$} & \multicolumn{2}{l|}{$\begin{array}{l}\text { t-test for Equality of } \\
\text { Means }\end{array}$} \\
\cline { 3 - 8 } & $\mathbf{F}$ & Sig. & t & $\begin{array}{l}\text { Sig. (2- } \\
\text { tailed) }\end{array}$ \\
\hline Shoulder Joint (Initial Phase) & Equal variances assumed & 9.498 &. $\mathbf{0 1 5}$ & 8.573 & 8 & .000 \\
\hline Wrist Joint (Initial Phase) & Equal variances assumed & 2.552 & .149 & .210 & 8 & .839 \\
\hline Elbow Joint (Initial Phase) & Equal variances assumed & 7.111 &. $\mathbf{0 2 9}$ & 1.000 & 8 & .347 \\
\hline Shoulder Joint (Ground Touch Phase) & Equal variances assumed & .419 & .535 & .596 & 8 & .568 \\
\hline Wrist Joint (Ground Touch Phase) & Equal variances assumed & .206 & .662 & 1.286 & 8 & .234 \\
\hline Elbow joint (Ground Touch Phase) & Equal variances assumed & 1.443 & .264 & -.286 & 8 & .782 \\
\hline
\end{tabular}

In the above table, Scholar firstly test equality of variances and for that Levene's Test was used. Table shows that shoulder joint at initial phase ( $F$ 9.498) and elbow joint at initial phase (F 7.111) which is significant as the p-value is .015 and .029 (shoulder joint and elbow joint at initial phase) which less the 0.05 . And rest of variables found Insignificant.

It can be seen that for testing the difference in the groups, the scholar used Independent $\mathrm{T}-$ Test which reveals that shoulder joint at initial phase with the value of $\mathrm{t}-8.573$, this value is significant as the $\mathrm{p}$ value is 0.000 . Which is less than 0.05 , In-spite this rest of the variable found Insignificant.

The stated test shown insignificant result because the sample size is small, level of performance of gymnasts and unavailability of sophisticated equipment's may also be one of the reasons of indicating insignificant result, some time environmental condition also affect the performance and it can also be one of the reason for insignificant result.

\section{CONCLUSIONS}

Based on the analysis and within the limitation of present study following conclusion were drawn:
- All the selected angular kinematical variables of Back Handspring and Forward Handspring, found insignificant.

\section{RECOMMENDATIONS}

Based on the conclusions drawn in this study, the following recommendations have been made:

1. The results of this study may be helpful for the analysis of other elements in gymnastics.

2. The results may be used by the gymnasts for selfevaluation of their photographic techniques.

3. Similar studies can be conducted by using cinematography and multidimensional photographic as well as the video graphic techniques.

4. The study may also be conducted on different age level, different performance level and also on different sex for comparing the performance.

\section{REFERENCES}

- Bawa, G. S. (1994). Fundamentals of Men's Gymnastics. New Dehli: Friends Publications.

- Bal, B. S., Kaur, P. J., \& Singh, D. (2011). The Relationship of the Selected Biomechanical Variables on the Performance of Kicking for Distance in Soccer, International Journal of Sports Science and Engineering, 5(4), 225-230. 
- Hall, S. J. (1995). Basic Biomechanics. McGrawHill-New Yark (2nd edition). 442-450.

- Hay, J. G. (1993). The Biomechanics of Sports Techniques. Englewood Cliffs N.J: Prentice Hall Inc.

- Hatze, H. (1974). The Meaning of the Term Biomechanics, Journal of Biomechanics, 7, 189190.

- Hay, J. G. (1984). Sports Biomechanics: a Study Report, Journal of Sports Sciences, 2.

- Chandra, J. H., Amar, K., \& Datt, G. G. (2014). Relationship Of Selected Kinematic Variables With The Performance Of Cast To Upper Arm Hang On Parallelbars In Men's Artistic Gymnastics. International Journal of Sports Sciences \& Fitness, 4(2), 166-176.
- Khalil, K. (1986). Effect of Approaches and TakeOff on the Vertical Jumps in Vollyball, Snipes Journal, 9(1), 1-7.

- Kumar, S., \& Bhardwaj, B. (2011). Relationship among Selected Biomechanical Variables with Lay-Up Shot Performance of Basketball Players, VSRD-TNTJ, 2(5), 229-233

- Kumar, D., Singh, M., \& Yadav, B. K. (2013). Relationship Between Selected Kinematical Variables and Performance of Instep Kick, International Journal of Physical Education, Sports and Yogic Sciences, 2(2), 61-63.

- Pandey, U., Patel, S., \& Saxsena, S. (2012). The Relationship of the Selected Kinematic Variables with the Performance of Low Dribble in Basketball at Execution Phase, Indian Journal of Science and Technology, 5(2), 20-22. 